\title{
Effort Estimation Menggunakan Metode Use Case Point untuk Pengembangan Perangkat Lunak
}

\section{(Studi Kasus Sistem Inventory Peminjaman Alat Laboratorium)}

\author{
Rifki Adhitama ${ }^{\# 1}$, Condro Kartiko ${ }^{\# 2}$ \\ \# Fakultas Teknologi Industri dan Informatika, Institut Teknologi Telkom Purwokerto \\ Jl. D.I Panjaitan 128 Purwokerto, Jawa Tengah, Indonesia \\ ${ }^{1}$ rifki@ittelkom-pwt.ac.id \\ ${ }^{3}$ condro.kartiko@ ittelkom-pwt.ac.id
}

Accepted on September 28, 2018

\begin{abstract}
Estimasi proyek perangkat lunak merupakan fase krusial yang dapat menentukan keberhasilan suatu proyek, dimana di dalamnya termasuk estimasi waktu pengerjaan, biaya dan sumberdaya manusia. Salah satu estimasi yang dilakukan dalam awal sebuah proyek perangkat lunak adalah software effort estimation atau estimasi resiko dan ukuran umum dari perangkat lunak yang akan dibuat pada sebuah proyek. Metode Use Case Points (UCP) merupakan metode software effort estimation yang menunjukkan performa yang lebih baik dibandingkan dengan metode lainnya. Penggunaan metode UCP dalam proyek perangkat lunak khususnya sistem inventory di indonesia dapat menjadi salah satu contoh dan acuan bagaiamana estimasi perangkat lunak inventory. Hasil dari penelitian ini adalah resiko dari proyek sistem inventory peminjaman alat laboratorium memiliki resiko kecil, dapat dikerjakan dalam waktu yang raltif singkat dan tidak membutuhkan sumberdaya yang banyak.
\end{abstract}

Keywords: Use Case Points, Effort Estimation, inventory system

\section{INTRODUCTION}

$\mathbf{S}^{\mathrm{s}}$ oftware effort estimation merupakan salah satu aspek penting yang menentukan keberhasilan suatu proyek perangkat lunak. Banyak proyek perangkat lunak yang gagal dikarenakan manajemen proyek yang buruk [1], termasuk di dalamnya adalah perhitungan estimasi software yang buruk. Estimasi yang tepat sangat menetukan keberhasilan suatu proyek perangkat lunak, jika estimasi terlalu rendah dari seharusnya maka akan berakibat pada tidak terselesaikannya proyek perangkat lunak karena waktu maupun biaya. Tetapi jika estimasi terlalu tinggi, maka akan menyebabkan proyek perangkat lunak menjadi tidak realistis untuk dilaksanakan.

Meskipun project effort estimation memgang peran yang sangat krusial pada keberhasilan proyek, tetapi masih banyak permasalahan yang terdapat pada software effort estimation seperti kurangnya informasi pada suatu proyek perangkat lunak di awal proyek tersebut sehingga menyebabkan sulitnya melakukan estimasi dari proyek perangkat lunak tersebut. Permasalahan lain yaitu keberlanjutan proyek yang terkadang masih belum 
dapat dipastikan, sehingga menuntut stakeholder untuk melakukan efisiensi sumberdaya, sehingga sumberdaya yang digunakan untuk estimasi menjadi tidak.

Estimasi proyek dapat dilakukan dengan beberapa cara, cost model seperti COCOMO, Function Point Analysis (FPA), Mark II Function Points [2] dan COSMIC [3] yang telah banyak digunakan pada industri, dimana kedua model ini menggunakan model estimasi parametrik dalam implementasinya. Meskipun telah banyak digunakan tetapi model ini masih memiliki kelemahan yaitu dibutuhkan orang yang telah memiliki pengalaman ataupun telah sangat paham dalam menghitung poin untuk tiap fungsi dari software yang di estimasi [1]. Untuk mengatasi kelemahan tersebut, dikembangkanlah sebuah metode untuk estimasi software yaitu "Use Case Point Estimation (UCP)". UCP dikembangkan oleh Gustav karner [4] untuk melakukan estimasi pada awal proyek perangkat lunak. Metode UCP merupakan sebuah estimasi awal berdasarkan dari use case diagram, dimana UCP dapat digunakan untuk melakukan memahami permasalahan yang mungkin terjadi pada perangkat lunak, estimasi ukuran proyek dan arsitektur umum sistem.

Di sisi lain, histori dan kejelasan data keluar masuk barang adalah hal yang amat penting dalam hal inventariasi. Masih banyak skema pencatatan inventaris di berbagai tempat masih menggunakan pencacatan manual, dimana hal ini rawan terhadap accidental disasater. Pembuatan sistem inventarisasi merupakan salah satu solusi dalam mengembangkan skema inventarisasi manual ayang telah ada, memberikan keamanan lebih, dan memberikan resistensi lebih terhadap accidental disaster yang mungkin terjadi.

Tujuan dari penelitian ini adalah membuat sebuah estimasi sistem inventarisasi barang dengan menggunakan metode estimasi UCP. Studi kasus yang digunakan adalah dalam proyek pembangunan sistem inventory peminjaman alat laboratorium. Dimana hasil dari penelitian ini diharapkan dapat menjadi salah satu contoh maupun acuan dalam pengembangan sistem inventarisasi barang lainnya. Sehingga masyarakat yang akan mengembangkan sebuah sistem inventarisasi memiliki gambaran umum yang jelas terhadap estimasi ukuran dan arsitektur umum dari sistem inventarisasi.

\section{LITERATURE REVIEW}

Use Case Point (UCP) merupakan pengembangan dari function point, dimana kelebihan dari UCP adalah pada teknik analisisnya yang berdasarkan object oriented process. UCP dikembangkan dari function point karena kelemahan dari function point yang membutuhkan terlalu banyak penilaian subjektif dari manusia [5], sehingga hasilnya menjadi kurang objektif. Pentingnya penggunaan Use Case Point (UCP) dalam pelaksanaan sebuah proyek perangkat lunak telah dibuktikan dengan pengukuran yang telah dilakukan Kusumoto S, dkk. Penelitian tersebut mengukur lima proyek perangkat lunak dengan menggunakan beberapa teknik pengukuran. Hasil dari penelitian tersebut menunjukkan bahwa teknik UCP menghasilkan hasil yang cukup memuaskan [6]. Penelitian lain yang telah dilakukan oleh Scneider dan Winters, Use Case Point (UCP) menunjukkan performa yang lebih baik dibandingkan teknik estimasi yang lainnya [7].

Penelitian lain dilakukan oleh Anda, dkk pada tahun 2002 [8], dimana penelitian tersebut meneliti tentang bagaimana metode UCP beradaptasi pada lingkungan proyek untuk meningkatkan proses dari software effort estimation pada proyek perangkat lunak. Penelitian tersebut meneliti penggunaan UCP pada beberapa proyek perangkat lunak, melakukan wawancara terhadap seluruh stakeholder dari proyek perangkat lunak yang berjalan tentang bagaimana menggunakan UCP. Hasil penelitian menunjukkan bahwa keakuratan estimasi merupkan hal yang sangat krusial dalam keberhasilan proyek perangkat lunak.

Kelebihan UCP dibandingkan dengan teknik estimasi yang lain juga pernah diteliti oleh Damodaran dan Aqua Nette. Dimana penelitian dari mereka fokus pada membandingkan function point dan UCP. Hasil dari penelitian tersebut adalah UCP lebih relevan digunakan dalam system modern yang menggunakan object oriented system yang menggunakan Use Case [9]. Penggunaan UCP pada sebuah proyek perangkat lunak dapat meproyeksikan estimasi 20\% lebih dini dibandingkan dengan estimasi dari ahli dan dan metode estimasi lainnya [10]. 


\section{RESEARCH METHOD}

Estimasi dalam metode UCP dimulai dengan melakukan pengukuran kompleksitas dari actor (Unadjusted Actor Weight) dan use case (Unadjusted Use Case Weight) yang ada di dalam sistem. Selanjutnya dilakukan pengukuran terhadap kompleksitas teknis (Techinical Complexity Factor) dan environtment (Environtmental Factor) sistem yang digunakan dalam pengembangan proyek perangkat lunak. Setelah itu baru dilakukan pengukuran terhadap Use Case Points, Productivity Factor dan Effort Estimation. Detail dari alur proses UCP adalah sebagai berikut.

1) Kompleksitas actor

Kompleksitas actor dalam metode pengukuran UCP dibagi kedalam tiga kategori yaitu

- Simple: merepresentasikan sistem yang berkomunikasi dengan sistem lainnya menggunakan Application Programming Interface (API).

- Average: merepresentasikan sistem yang berkomunikasi dengan actor lainnya menggunakan protocol khusus seperti HTTP dan FTP, ataupun manusia yang berkomunikasi dengan sistem menggunakan terminal console.

- Complex: Manusia yang menggunakan Graphical User Interface (GUI) untuk berkomunikasi dengan sistem.

Untuk masing masing kelas yang dideskripsikan sebelumnya dilakukan perhitungan Unadjusted Actor Weight (UAW) atau penghitungan bobot masing-masing actor, dimana aturan pembobotan adalah tiga (3) untuk actor complex, dua (2) untuk actor medium dan satu (1) untuk actor simple. Untuk perhitungan rumus UAW adalah sebagai berikut

$$
\text { UAW : } \sum \text { bobot (c) x jumlah actor }(c)
$$

dimana:

c: kelas dari aktor yang bersangkutan \{simple, medium, complex\}

2) Kompleksitas Use Case

Langkah selanjutnya adalah mengukur kompleksitas Use Case. Berbeda dengan kompleksitas actor, kompleksitas use case diukur berdasarkan kompleksitas transaksi dari masing-masing use case. Transaksi di dalam use case merupakan aktivitas /skenario yang terdapat dalam masing-masing use case. Kompleksitas transaksi dari use case dibagi ke dalam tiga (3) kategori yaitu.

$$
\text { kompleksitas use case }\left\{\begin{array}{c}
\text { simple jika transaksi }<4 \\
\text { average jika } \leq 4 \text { transaksi } \leq 7 \\
\text { complex jika transaksi }>7
\end{array}\right.
$$

Untuk masing-masing kelas yang dideskripsikan dilakukan perhitungan kompleksitas use case dengan menghitung Unadjusted Use Case Weight (UUCW), dimana aturan pembobotan adalah lima (5) untuk simple use case, sepuluh (10) untuk average use casae dan lima belas (15) untuk complex use case. Untuk perhitungan rumus UUCW adalah sebagai berikut

dimana:

$$
\text { UUCW: } \sum \text { bobot (c) x jumlah use case (c) }
$$

c: kelas dari use case bersangkutan $\{$ simple, average, complex $\}$

3) Faktor teknis dan environtment pengembangan perangkat lunak

Metode UCP menggunakan dua puluh satu (21) pengukuran untuk mengukur factor teknis dan environment pengembangan sistem yang dibagi menjadi tiga belas (13) parameter untuk mengukur teknis sistem (Technichal Complexity Factors) dan delapan (8) parameter untuk mengukur environment pengembangan sistem (Environtmental Factors). Detail dari Technical Complexity Factor ditunjukkan pada Tabel I dan Environtmental Factors ditunjukkan pada Tabel II 
TABEL I

TECHNICAL COMPLEXITY FACTORS

\begin{tabular}{|c|l|c|}
\hline \multicolumn{3}{|c|}{ Technical Complexity factors } \\
\hline Factor & \multicolumn{1}{|c|}{ Description } & Weight \\
\hline T1 & Distributed System & 2 \\
\hline T2 & Performance & 1 \\
\hline T3 & End-User Efficiency & 1 \\
\hline T4 & Complex processing & 1 \\
\hline T5 & Reusable code & 1 \\
\hline T6 & Easy to install & 0.5 \\
\hline T7 & Easy to use & 0.5 \\
\hline T8 & Portable & 2 \\
\hline T9 & Easy to change & 1 \\
\hline T10 & Concurrent & 1 \\
\hline T11 & Security features & 1 \\
\hline T12 & Access for third parties & 1 \\
\hline T13 & Special training required \\
\hline
\end{tabular}

TABEL II

ENVIRONTMENTAL COMPLEXITY FACTORS

\begin{tabular}{|c|l|c|}
\hline \multicolumn{3}{|c|}{ Environtmental Complexity factors } \\
\hline Factor & \multicolumn{1}{|c|}{ Description } & Weight \\
\hline F1 & Familiarity with standart process & 1.5 \\
\hline F2 & Application experience & 0.5 \\
\hline F3 & Object-oriented experience & 1 \\
\hline F4 & Lead analyst capability & 0.5 \\
\hline F5 & Motivation & 1 \\
\hline F6 & Stable requirements & 2 \\
\hline F7 & Part-time workers & -1 \\
\hline F8 & Difficult programming language & -1 \\
\hline
\end{tabular}

Pengaruh Technical Complexity Factor (TCF) pada metode pngukuran UCP berada di rentang antara nol (0) sampai lima (5), dimana makin besar pengaruh dari faktor yang bersangkutan dalam pengerjaan proyek, maka makin besar pula nilai estimasi pengaruhnya. Perhitungan TCF adalah mengalikan bobot penilaian pengaruh, dengan bobot yang telah ditentukan pada Tabel I. Formula untuk perhitungan UCF adalah sebagai berikut.

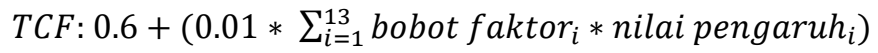

Sedangkan pengaruh Environtmental Factor $(E F)$ dilakukan perhitungan yang sama dengan TCF, yaitu memberikan nilai estimasi pada setiap faktor sesuai dengan pengaruhnya pada rentang nol (0) sampai lima (5) kemudian dikalikan dengan bobot masing-masing factor sesuai Tabel II. Formula untuk perhitungan EF adalah sebagai berikut.

$$
E F: 1.4+\left(-0.03 * \sum_{i=1}^{8}{\text { bobot } \text { faktor }_{i} * \text { nilai pengaruh }}_{i}\right)
$$

4) Use Case Points

Untuk menghitung Use Case Point, harus dilakukan perhitungan Unadjusted Use Case Point (UUCP) dengan menambahkan Unadjusted Actor Weight (UAW) dengan Unadjusted Use Case Weight $(U U C W)$. Formula untuk menghitung UUCP ditunjukkan pada formula (5).

$$
\text { UUCP: } U A W+U U C W
$$


Setelah didapatkan UUCW maka dilakukan perhitungan Use Case Point dengan formula yang ditunjukkan pada formula (6).

dimana:

$U C P: U U C P * T C F * E F$

UUCP : Unadjusted Use Case Points

TCF : Technical Complexity Factors

EF : Environtment Factor

5) Productivity Factor dan Effort Estimation

Nilai effort estimation didapatkan dari perkalian antara Productivity Factor dengan nilai UCP. Untuk mendapatkan nilai productivity factor menurut perhitungan Scneider dan Winters adalah jika Nilai EF $\leq$ dua (2) maka nilai productivity factor adalah 20 untuk setiap UCP, jika nilai EF berada pada rentang tiga (3) dan empat (4) maka nilai productivity factor adalah 28 untuk setiap UCP, jika nilai EF lebih dari 4 maka nilai productivity factor yang digunakan adalah 36 untuk setiap UCP [7].

\section{RESULTS AND DISCUSSION}

Pada penelitian ini teknik UCP diimplementasikan pada sistem inventory peminjaman alat laboratorium komputer untuk mengetahui secara umum, effort dan resiko pada proyek perangkat lunak inventory peminjaman alat laboratorium. Use Case sistem inventory laboratorium pada studi kasus penelitian ini ditunjukkan pada Gambar I.

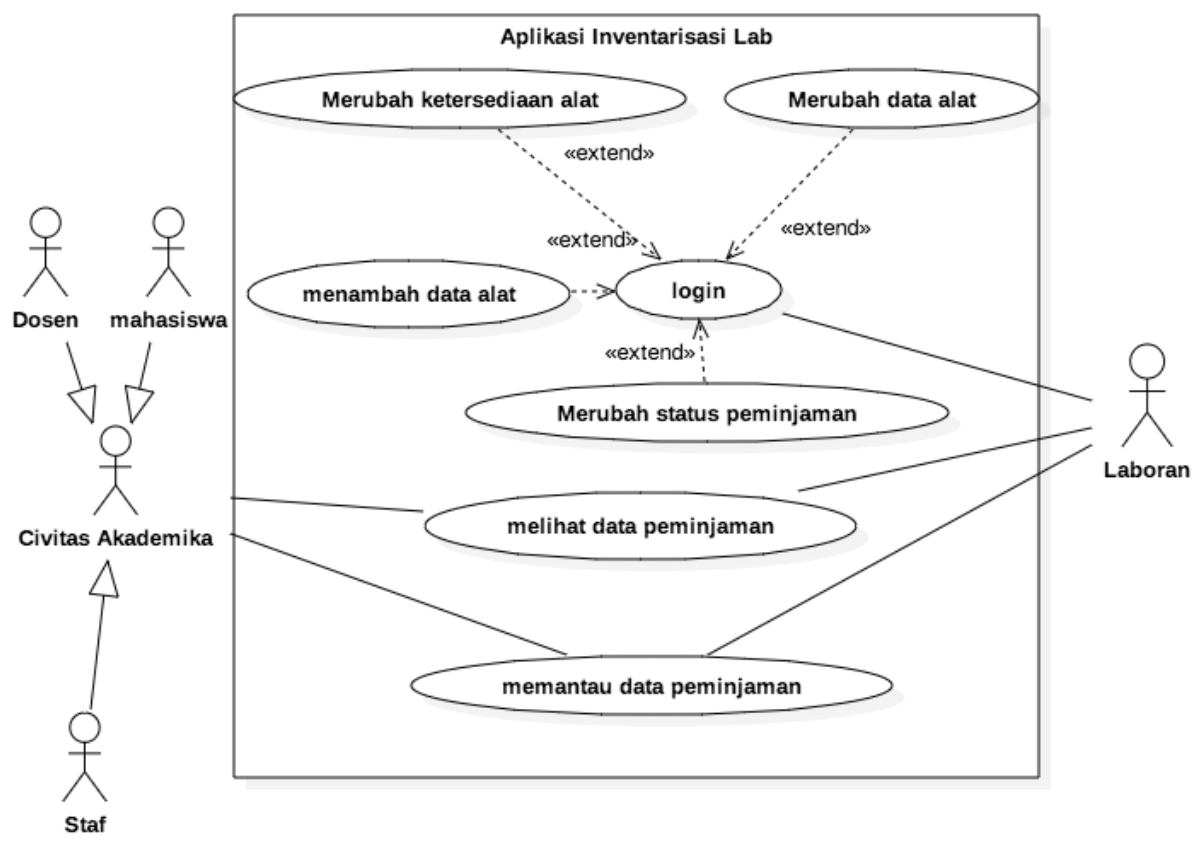

Gambar. 1. Use Case sistem inventory peminjaman alat laboratorium komputer

Dalam use case sistem inventory peminjaman alat laboratorium terdapat tujuh (7) use case dengan dua (2) aktor utama yaitu laboran dan civitas akademika yang terdiri dari staf, dosen dan mahasiswa. Behavior sistem terhadap staf, dosen dan mahasiswa adalah sama, maka dari itu ketiga sub-aktor tersebut digeneralisasi menjadi civitas akademika. Langkah-langkah proses estimasi UCP pada sistem inventory peminjaman alat laboratorium dijabarkan pada poin-poin berikut:

1) Kompleksitas actor 
Actor pada sistem ini dibagi menjadi dua (2), dimana kedua actor dalam sistem inventory peminjaman alat laboratorium merupakan manusia sehingga digolongkan ke dalam complex actor yang memiliki bobot tiga (3). Detail perhitungan Unadjusted Actor Weight (UAW) pada sistem inventory peminjaman alat laboratorium ditunjukkan pada Tabel III.

TABEL III

UNADJUSTED ACTOR WEIGHT

\begin{tabular}{|l|c|c|c|}
\hline \multicolumn{4}{|c|}{ UAW } \\
\hline \multicolumn{1}{|c|}{ kelas } & Jumlah actor & bobot & Jumlah actor * bobot \\
\hline Simple & 0 & 1 & 0 \\
\hline Medium & 0 & 2 & 0 \\
\hline Complex & 2 & 3 & 6 \\
\hline \multicolumn{3}{|c|}{ Total UAW } & 6 \\
\hline
\end{tabular}

2) Kompleksitas Use Case

Sistem inventory peminjaman alat laboratorium pada penelitian ini memiliki tujuh (7) use case yaitu login, merubah data alat, merubah ketersediaan alat, menambah data alat, merubah status peminjaman, melihat data peminjaman dan memantau data peminjaman. Tujuh (7) use case tersebut akan dibagi ke dalam tiga (3) kelas yaitu simple, average dan complex berdasarkan jumlah transaksi yang ada didalamnya untuk mendapatkan Unadjusted Use Case Weight (UUCW). Detail dari pembagian use case berdasarkan kompleksitasnya ditunjukkan pada Tabel IV dan hasil UUCW ditunjukkan pada Tabel V.

TABEL IV

PEMBAGIAN KOMPLEKSITAS USE CASE

\begin{tabular}{|l|c|c|}
\hline \multicolumn{1}{|c|}{ Use Case } & transaksi & kelas \\
\hline Login & 2 & Simple \\
\hline Merubah data alat & 4 & Average \\
\hline Merubah ketersediaan alat & 4 & Average \\
\hline Menambah data alat & 5 & Average \\
\hline Merubah status peminjaman & 3 & Average \\
\hline Melihat data peminjaman & 2 & Simple \\
\hline Memantau data peminjaman & 2 & Simple \\
\hline
\end{tabular}

TABEL V

UNADJUSTED USE CASE WEIGHT

\begin{tabular}{|l|c|c|c|}
\hline \multicolumn{4}{|c|}{ UUCW } \\
\hline \multicolumn{1}{|c|}{ kelas } & Jumlah use case & bobot & Jumlah use case * bobot \\
\hline Simple & 3 & 5 & 15 \\
\hline Average & 4 & 10 & 40 \\
\hline Complex & 0 & 15 & 0 \\
\hline \multicolumn{3}{|c|}{ Total UUCW } & 55 \\
\hline
\end{tabular}

3) Faktor teknis dan environtment pengembangan perangkat lunak

Proses selanjutnya adalah menghitung Technical Complexity Factor (TCF) dan Environtment Factor (EF). Pembobotan estimasi pengaruh factor dari TCF dan EF dilakukan pada rentang nol (0) sampai lima (5), dimana makin tinggi pengaruh /impact dari factor tersebut maka sekain tinggi pula bobot estimasinya. Detail dari pembobotan TCF dapat dilihat pada Tabel VI.

TABEL VI

TECHNICAL COMPLEXITY FACTORS 


\begin{tabular}{|c|l|c|c|c|}
\hline \multicolumn{5}{|c|}{ Technical Complexity factors } \\
\hline Factor & \multicolumn{1}{|c|}{ Description } & Bobot & impact & Bobot * impact \\
\hline T1 & Distributed System & 2 & 2 & 4 \\
\hline T2 & Performance & 1 & 5 & 5 \\
\hline T3 & End-User Efficiency & 1 & 3 & 3 \\
\hline T4 & Complex processing & 1 & 1 & 1 \\
\hline T5 & Reusable code & 1 & 4 & 4 \\
\hline T6 & Easy to install & 0.5 & 4 & 2 \\
\hline T7 & Easy to use & 0.5 & 4 & 2 \\
\hline T8 & Portable & 2 & 3 & 6 \\
\hline T9 & Easy to change & 1 & 2 & 2 \\
\hline T10 & Concurrent & 1 & 2 & 2 \\
\hline T11 & Security features & 1 & 2 & 3 \\
\hline T12 & Access for third parties & 1 & 2 & 2 \\
\hline T13 & Special training required & 1 & 3 \\
\hline \multicolumn{2}{|c|}{ Total Factor } \\
\hline
\end{tabular}

Dari Tabel VI, maka didapatkan nilai TCF adalah.

$$
\begin{aligned}
T C F & : 0.6+(0.01 * 38) \\
& : 0.98
\end{aligned}
$$

Sedangkan untuk detail pembobotan EF ditunjukkan pada Tabel VII.

TABEL VII

ENVIRONTMENTAL COMPLEXITY FACTORS

\begin{tabular}{|c|l|c|c|c|}
\hline \multicolumn{5}{|c|}{ Environtmental Complexity factors } \\
\hline Factor & \multicolumn{1}{|c|}{ Description } & Weight & impact & Bobot * impact \\
\hline F1 & Familiarity with standart process & 1.5 & 3 & 4.5 \\
\hline F2 & Application experience & 0.5 & 2 & 1 \\
\hline F3 & Object-oriented experience & 1 & 3 & 3 \\
\hline F4 & Lead analyst capability & 0.5 & 3 & 1.5 \\
\hline F5 & Motivation & 1 & 1 & 1 \\
\hline F6 & Stable requirements & 2 & 3 & 6 \\
\hline F7 & Part-time workers & -1 & 4 & -4 \\
\hline F8 & Difficult programming language & -1 & 4 & -4 \\
\hline \multicolumn{2}{|c|}{ Total Factor } & & 9 \\
\hline
\end{tabular}

Dari Tabel VII, maka didapatkan nilai EF adalah.

$$
\begin{aligned}
& E F: 1.4+(-0.03 * 9) \\
& \quad: 1.13
\end{aligned}
$$

4) Use Case Points

Tahapan selanjutnya adalah menghitung use case points dengan mengalikan UUCW dengan TCF dan $\mathrm{EF}$, hasil dari perhitungan UUCP adalah sebagai berikut.

$$
\begin{aligned}
U U C P & : U A W+U U C W \\
& : 6+55 \\
& : 61
\end{aligned}
$$

Sehingga nilai UCP adalah sebagai berikut

$$
\begin{aligned}
U C P & : U U C P * T C F * E F \\
& : 61 * 0.98 * 1.13 \\
& : 67
\end{aligned}
$$

5) Productivity Factor dan Effort Estimation 
Berdasarkan perhitungan nilai EF maka nilai productivity yang digunakan adalah 20 jam untuk setiap UCP dimana resiko proyek pengerjaan tergolong rendah dan effort estimation dari pengerjaan adalah 1340 jam pengerjaan.

\section{CONCLUSION}

Pembangunan sistem inventory peminjaman alat laboratorium pada studi kasus yang digunakan dalam penelitian ini membutuhkankurang lebih 1340 jam pengerjaan, dengan resiko pengerjaan proyek yang tergolong rendah. Jika diasumsikan pengerjaan dengan tim yang berisi tiga (3) orang dengan jam pengerjaan tiga puluh (30) jam per minggu maka proyek ini seharusnya selesai dalam empat belas (14) minggu pengerjaan.

Secara umum resiko pembangunan sistem inventory tidak tinggi, waktu pengerjaan yang relative singkat dan tim yang dibutuhkan tidak banyak. Penelitian ini dapat dikembangkan dengan mengkur hasil actual dari pembuatan keseluruhan sistem, dan menggunakan metode UCP untuk estimasi model sistem inventory yang lain di indonesia, sehingga dapat diperkirakan rerata effort yang diperlukan dalam pembuatan inventory system.

\section{ACKNOWLEDGMENT}

Penulis berterimakasih kepada Institut Teknologi Telkom Purwokerto yang telah memberikan dukungan pada penelitian ini di bawah hibah untuk penelitian internal - Tahun 2018 (Nomor: IT Tel 1016/LPPM000/Ka. LPM/IV/2018)

\section{REFERENCES}

[1] P. P. Jena and S. Mishra, "Survey Report on Software Cost Estimation using Use Case Point Method," International Journal of Computer Science \& Engineering Technology (IJCSET), vol. 5, no. 4, pp. 280-287, 2014.

[2] S. C.R, Software Sizing and Estimating: Mk II FPA (Function Point Analysis), New York, NY: John Wiley \& Sons, Inc, 1991.

[3] A. Abran, S. Oligny, C. Symsons and J. M. Desharnais, "Functional Size Measurements Method - COSMIC - FFP; Design and Field Trials," in FESMA-AEMES Software Measurements Conference 2000, 2000.

[4] M. M. Kirmani and A. Wahid, "Use Case Point Method of Software Effort Estimation: A Review," International Journal of Computer Applications, vol. 116, no. 15, pp. 43-47, 2015.

[5] K. G, "Metrics for Objectory," University of Linkoping, Sweden, 1993.

[6] S. Kusumoto, M. Tsuda and K. Inoue, "Use Case Points Measurement Tool for Effective Project Management," in 14th Asia-Pacific Software Engineering Conference (APSEC'07), Aichi, Japan, 2007. 
[7] G. Schneider and J. P. Winters, Applying Use Cases: A Practical Guide (2nd Edition), Boston, Massachusetts: Addison-Wesley Professional, 2001.

[8] B. Anda, E. Angelvik and K. Ribu, "Improving Estimation Practices by Applying Use Case Models," in International Conference on Product Focused Software Process Improvement, Rovaniemi, Finland, 2002.

[9] M. Damodaran and A. N. E. Washington, Estimation Using Use Case Points, Texas, Victoria: University of Houston, 2002.

[10] R. K. Clemmons, "Project estimation with use case points," The Journal of Defence Software Engineering, pp. 18-22, 2006. 